\title{
Typical hierarchical processing in autistic adults
}

Skripkauskaite, Simona; Slade, Lance; Mayer, Jennifer

\section{Journal of Cognitive Psychology}

\author{
DOI: \\ 10.1080/20445911.2020.1749061
}

Published: 18/05/2020

Peer reviewed version

Cyswllt i'r cyhoeddiad / Link to publication

Dyfyniad o'r fersiwn a gyhoeddwyd / Citation for published version (APA):

Skripkauskaite, S., Slade, L., \& Mayer, J. (2020). Typical hierarchical processing in autistic adults. Journal of Cognitive Psychology, 32(4), 442-448.

https://doi.org/10.1080/20445911.2020.1749061

\footnotetext{
Hawliau Cyffredinol / General rights

Copyright and moral rights for the publications made accessible in the public portal are retained by the authors and/or other copyright owners and it is a condition of accessing publications that users recognise and abide by the legal requirements associated with these rights.

- Users may download and print one copy of any publication from the public portal for the purpose of private study or research.

- You may not further distribute the material or use it for any profit-making activity or commercial gain

- You may freely distribute the URL identifying the publication in the public portal ?
}

Take down policy

If you believe that this document breaches copyright please contact us providing details, and we will remove access to the work immediately and investigate your claim. 


\title{
Brief Article:
}

\section{Typical Hierarchical Processing in Autistic Adults}

\author{
Simona Skripkauskaite ${ }^{1}$ \\ University of Roehampton \\ Lance Slade ${ }^{2}$ \\ University of Roehampton and Canterbury Christ Church University \\ Jennifer Mayer \\ University of Roehampton
}

Correspondence concerning this article should be addressed to Simona

Skripkauskaite, School of Psychology, Bangor University, Brigantia Building, Penrallt Road, LL57 2AS Bangor, Gwynedd, United Kingdom. E-mail: s.skripkauskaite@bangor.ac.uk. Tel: +441248388797

\footnotetext{
${ }^{1}$ Simona Skripkauskaite is now at affiliation with School of Psychology, Bangor University, Bangor, Gwynedd, United Kingdom.

${ }^{2}$ Lance Slade is now at School of Psychology, Politics and Sociology, Canterbury Christ Church University, Kent, United Kingdom.
} 


\begin{abstract}
Previous research suggests that autistic individuals exhibit atypical hierarchical processing, however, most of these studies focused solely on children. Thus, the main aim of the current study was to investigate the presence of atypical local or global processing in autistic adults using a traditional divided attention task with Navon's hierarchical figures. Reaction time data of 27 autistic and 25 neurotypical (NT) adults was analysed using multilevel modelling and Bayesian analysis. The results revealed that autistic, like NT, adults experienced a global precedence effect. Moreover, both autistic and NT participants experienced global and local interference effects. In contrast to previous findings with children, the current study suggests that autistic adults exhibit a typical, albeit unexpected, processing of hierarchical figures.
\end{abstract}

Keywords: autism, adults, hierarchical processing, visual perception 


\section{Introduction}

Autism spectrum disorders (ASD) have been suggested to be associated with a bias towards (Happé \& Frith, 2006) or superiority in (Mottron, Dawson, Soulières, Hubert, \& Burack, 2006) detail-oriented processing style. Indeed, autistic individuals also excel at detail-oriented tasks. For example, above typical performance during embedded figures has been observed in autistic individuals (e.g. Shah \& Frith, 1983) and broader autism phenotype (see Cribb, Olaithe, Di Lorenzo, Dunlop, \& Maybery, 2016). Similarly, autistic individuals exhibit superior abilities in a block design tasks (e.g. Ropar \& Mitchell, 2001; Shah \& Frith, 1993), when copying impossible figures (Mottron, Burack, Iarocci, Belleville, \& Enns, 2003), and detecting local targets (Plaisted, O’Riordan, \& Baron-Cohen, 1998) or ignoring an increasing numbers of distractors (O'Riordan, Plaisted, Driver, \& Baron-Cohen, 2001) in visual search tasks. However, they also appear to be less efficient when utilizing gestalt grouping rules (Scherf, Luna, Kimchi, Minshew, \& Behrmann, 2008) and succumb less to visual illusions (Happé, 1996). Taken together, these findings indicate that autistic individuals may focus more on the components of a stimulus than on the global entity or whole. Atypical integration of local/global information may underlie differences in face perception, sensory processing, and social interactions in ASD. Yet, partially due to the use of different versions of hierarchical perception tasks, it remains unclear whether this atypicality indeed represents an universal autistic trait (Simmons \& Todorova, 2018).

Hierarchical perception can be tested using stimuli with information at both the global (i.e. the overall shape) and local level (i.e. individual elements). The most frequently used example of such stimuli is the Navon's (1977) hierarchical figures task with two stimulus levels comprising of large shapes made up from the smaller ones (Figure 1). The stimuli can be congruent or incongruent and have the target letter presented at the local or global levels respectively or both. Typical performance on this task usually results in two effects. Firstly, 
participants experience a global interference effect where an incongruent large (global) letter slows down the identification of the small (local) target letter when compared to trials with congruent stimuli. When the target is presented at the global level, on the other hand, a global precedence effect occurs where local interference effect from incongruent small letter is reduced in comparison to the global intereference effect (i.e. reponses to incongruent trials with global target are faster than to incongrient trials with local target). Hence, this task is thought to represent faster global information processsing and show that global information is typically available earlier than local information (Navon, 1977).

[Figure 1 near here]

Multiple studies using traditional Navon's tasks find atypical local processing in autistic children and adolescents (e.g. Rinehart, Bradshaw, Moss, Brereton, \& Tonge, 2000), while others do not (Mottron et al., 2003; Ozonoff, Strayer, McMahon, \& Filloux, 1994). Plaisted, Swettenham, and Rees (1999) suggested that such inconsistencies were likely to have been due to methodological differences across studies. To be precise, they observed that this occurred only in divided attention tasks where one monitors both levels of the figures and responds when the target letter appeared at either level. The alternative, a selective attention version of the task, has participants focusing only on the local or global level of the figure at a time. In contrast to divided attention tasks, selective attention tasks did not yield atypical performance. Therefore, it appears that autistic children and adolescents demonstrate atypical hierarchical processing, but only in one version of the task.

Adult studies differ from those focused on children not only in the age of the sample used, but also the task chosen. In their meta-analysis, Van der Hallen, Evers, Brewaeys, Van den Noortgate, and Wagemans (2015) found inconsistent or weak evidence for atypical local and global processing in ASD, with stronger effects occurring for Navon's figures tasks. They also observed subtle age differences in the performance of autistic and neurotypical 
(NT) participants. Yet, a clear pattern for age differences could not be determined as only two out of nine studies using Navon's figures included adults. Both also utilized a selective rather than divided attention version of the task. Other research studying hierarchical processing in autistic adults used even further variations of the task (e.g. Rondan \& Deruelle, 2007). It is noteworthy that different paradigms measuring local/global bias poorly relate to each other even in NTs (Dale \& Arnell, 2013; Van Eylen, Boets, Steyaert, Wagemans, \& Noens, 2018). Hence, it is plausible that due to use of different tasks evidence of atypicalities observed in autistic children and adults to date are tapping into distinct aspects of hierarchical processing. In summary, Plaisted et al. (1999) revealed that task demands can moderate the presence of atypical hierarchical processing in autistic children and adolecsents with only the divided attention task revealing a lack of global advantage. Yet, to our knowledge, it has not been established whether the existence of this atypical processing in a divided attention task extends to autistic adults.

The primary aim of the present study was, therefore, to investigate whether atypical hierarchical processing occurs in autistic adults using the traditional divided attention task with Navon's figures. This atypical perception of hierarchical structures has been primarily addressed by two theories: Weak Central Coherence (Frith, 1989; WCC; Frith \& Happé, 1994; Happé \& Frith, 2006) and Enhanced Perceptual Functioning (EPF; Mottron \& Belleville, 1993; Mottron et al., 2006). WCC posits a detail-focused processing style (i.e. stronger local interference) with potentially weaker global processing (i.e. weaker global interference) in autism, which may reflect a bias towards local processing and in turn a local precendence effect (Happé \& Frith, 2006). EPF, in contrast, suggests that atypical behaviour exhibited by autistic individuals does not represent a weakness in global perception (i.e. intact global interference and precedence), but rather a superiority in low-level perception (i.e. stronger local interference) and optional higher-order processing (Mottron \& Belleville, 
1993). Thus, it was expected that NT adults would exhibit a global interference (i.e. respond to local target trials slower than the congruent stimuli) and a global precedence (i.e. respond to global target trials faster than local target trials) effects. Autistic adults, however, were expected to exhibit atypical local interference effect (i.e. respond to global target trials slower than the congruent stimuli) in one of two ways: 1) due to larger than typical local interference effect show a local precedence effect (i.e. respond to local target trials faster than global target trials) in line with theory of Weak Central Coherence (WCC; Happé \& Frith, 2006) or 2) show a larger than typical local interference effect but still exhibit global precedence and intact global interference effect according to Enhanced Perceptual Functioning theory (EPF; Mottron et al., 2006). 


\section{Materials and Methods}

\section{Participants}

Participants were recruited through an opportunity sample or advertising online and reimbursed for their time in the study ( $£ 8$ per hour). All autistic participants were highfunctioning (IQ > 70; Levy \& Perry, 2011) and had a pre-existing ASD diagnosis, which was further evaluated using ADOS-2 Module 4 (Lord et al., 2012). All the participants were living without direct support, were able to travel independently, and had normal or corrected to normal vision.

The sample consisted of 27 autistic (14 females) and 25 NT (13 females) adults. The groups were matched on gender $\left(\chi^{2}(1)<0.01, p=.991\right)$, age, and IQ, but not their AutismSpectrum Quotient (AQ; Baron-Cohen, Wheelwright, Skinner, Martin, \& Clubley, 2001) scores (Table 1). Informed written consent was obtained from all individual participants included in the study. The study was conducted in accordance with the ethical standards of University of Roehampton Ethical Committee.

[Table 1 near here]

\section{Materials and Procedure}

The task was presented using a 40x30 cm (1152x864 px) CRT monitor with a white background. Sixteen monochrome Navon's hierarchical figures with large letters comprised of smaller letters were used as the stimuli (Figure 1). Four of the stimuli were congruent (e.g. S at both levels) and 12 were incongruent (e.g. big H made up of smaller X's). The letters measured at $3.43 \times 5.01 \mathrm{~cm}\left(2.44^{\circ} \times 3.55^{\circ}\right)$ for the global, and $0.39 \times 0.39 \mathrm{~cm}\left(0.27^{\circ} \times 0.27^{\circ}\right)$ for the local, level.

Participants were instructed to indicate whether the target letter was present or absent on the screen in each trial. They first completed a feedback-based training session. The training session involved repeating a 27-trial block with a letter $\mathrm{T}$ as a target until $>80 \%$ 
accuracy per block was achieved. Then the task was presented in a 4 (letter-based block: A, $\mathrm{H}, \mathrm{S}$, or X) x 2 (presence of the target: present or absent) x 3 (target presentation level: congruent, global, or local) within-subject design. Each randomised letter block included 36 trials (144 trials in total) with 18 target present (6 congruent, 6 global, and 6 local) and 18 target absent (6 congruent and 12 incongruent) trials. Each stimulus was preceded by a fixation cross for $1000 \mathrm{~ms}$. The vertical position of the stimulus was randomised to appear either at $5.37^{\circ}(7.56 \mathrm{~cm})$ above or below the fixation point. The stimulus remained on the screen until the participant responded using the response box (target absent/present response).

\section{Data Analysis}

The analysis was conducted in two stages. Firstly, multilevel modelling was carried out to see whether different stimuli conditions affected participants' performance. The RT data was analysed in R using multilevel modelling with 2 (ASD or NT) x 3 (congruent, global, or local) design (nlme package; Pinheiro, Bates, DebRoy, \& Sarkar, 2016). Post hoc Tukey's HSD pairwise comparisons were carried out when applicable (emmeans package; Lenth, 2018).

Multilevel modelling (also known as hierarchical linear models or mixed-effect models) is a versatile statistical approach for analysing data that has a hierarchical data structure or for which assumptions of independence are likely to be violated (Field \& Wright, 2011). This modelling enabled a comprehensive comparison across conditions via the inclusion of main and interaction effects. This allows an examination of whether global interference (i.e. RTs slower in local than the congruent condition), local interference (i.e. RTs slower in global than the congruent condition), global precedence (i.e. RTs faster in global than local condition), or local precedence (i.e. RTs faster in local than global condition) took place across the participant groups. In comparison to more traditional repeated measures ANOVA, multilevel modelling not only allows to directly model within- 
participant dependence between conditions, but also does not require balanced data (Field \& Wright, 2011; Hox, 2010). The number of measurements can vary per participant (no need for listwise deletion due to missing data) and the number of participants can vary per group (Tabachnick \& Fidell, 2007).

As a non-significant result is unlikely to provide conclusive evidence for the null hypothesis and may instead represent insensitivity of the data (Dienes, 2014), a post hoc Bayesian analysis was conducted to confirm the findings of multilevel modelling and to quantify the evidence in favour of the data supporting $\mathrm{H}_{1}$ rather than $\mathrm{H}_{0}$. Therefore, $\mathrm{t}$, we additionally performed a Bayesian analysis for a 2 (ASD or NT) x 3 (congruent, global, or local) ANOVA (JASP Team, 2018). A Bayes Factor $\left(\mathrm{BF}_{10}\right)$ was calculated for each main and interaction effect to quantify the evidence in favour of the data supporting $\mathrm{H}_{1}$ rather than $\mathrm{H}_{0}$. Typically, Bayes factors $\left(\mathrm{BF}_{10}\right)<0.33$ provide substantial evidence for the null over the alternative hypothesis, $\mathrm{BF}_{10}>3$ can be interpreted as evidence for the alternative over the null hypothesis (Wagenmakers, Wetzels, Borsboom, \& van der Maas, 2011). 


\section{Results}

All participants successfully completed the training. Autistic participants took on average $1.41(S D=1.37)$ attempts at training session to achieve the $>80 \%$ accuracy, whilst NT participants took $1.04(S D=0.20)$ attempts on average, $t(27.20)=-1.38, p=.178$. Only correct responses to trials encompassing a target letter (72 trials) were included in the analysis as there were no group differences in error rates (ASD: $M=5.56, S D=7.39$; NT: $M=4.04, S D=6.96), t(50)=-0.76, p=.451$. To correct for normality violations, log-transformed (with the basis of 10) data was used in the analysis. For the ease of interpretation raw mean RTs and standard deviations are reported (Table 2).

[Table 2 near here]

\section{Multilevel Modelling}

Modelling results revealed a significant main effect of target presentation level, $F(2,3399)=253.37, p<.001, \eta^{2}=.13$. RTs in the congruent presentation $(M=706.15$, $S D=335.21)$ were shorter than RTs in incongruent trials with the target letter at the global level $(M=811.76, S D=376.98, t(3999)=-12.85, p<.001, r=.21)$ or the local level $(M=896.77$, $S D=376.75, t(3999)=-22.36, p<.001, r=.36)$. Therefore, on average, both local and global interference occurred. Post hoc comparisons also showed a presence of global preference effect as indicated by the significant difference between the RTs to incongruent trials with the target letter presented at the global and local levels, $t(3999)=-9.42, p<.001, r=.16$.

Neither the main nor interaction effects of diagnosis, however, reached significance. Autistic participants did not differ on average RT from NT participants, $F(1,50)=0.56$, $p=.457, \eta_{\mathrm{p}}^{2}=.01$. The diagnosis also did not moderate the effect of the target presentation level on participants' RTs, $F(2,3399)=1.11, p=.329, \eta_{\mathrm{p}}^{2}<.01$. In other words, the extend of local and global interference or global precedence did not significantly differ between autistic and NT participants. 


\section{Bayesian Analysis}

The largest Bayes factor $\left(\mathrm{BF}_{10}=1.73 \mathrm{e}+26\right)$ showing extreme evidence (more than 100 times likely; Wagenmakers et al., 2011) for an alternative rather than null hypothesis was received for the target presentation level model. The model with diagnosis on its own $\left(\mathrm{BF}_{10}=0.48\right)$, however, was around 2.08 times less likely than the null model. The model including both the main effect of target presentation level and diagnosis was also much more likely than null model $\left(\mathrm{BF}_{10}=1.09 \mathrm{e}+26\right)$, but 1.59 times less likely than the target presentation level only model. Adding the interaction made the model substantially less competitive as the data was 5.25 times less likely under the model that adds the interaction than the two main effects model. Therefore, in line with multilevel modelling, the data was most likely for the model with the main effect of the target presentation level only. 


\section{Discussion}

The aim of the present study was to investigate hierarchical processing in autistic adults using a traditional Navon's task. As expected, NT adults exhibited both global interference and global precedence effects by responding slower to incongruent than congruent trials especially when the target occurred at the local level. In contrast to both WCC and EPF hypothesis, however, autistic adults exhibited a typical local interference effect. To be precise, they also showed a global interference and precedence effects, which did not differ from those observed in NT adults. Thus, the current study shows that autistic, just like NT, adults experienced both local and global interference with global precedence when processing hierarchical stimuli.

Previous research has suggested that autistic individuals differ from NT individuals when processing hierarchical stimuli (Plaisted et al., 1999; Rinehart et al., 2000; Rondan \& Deruelle, 2007). Existent theories have focused on a bias to (WCC; Happé \& Frith, 2006) or superiority of (EPF; Mottron et al., 2006) local processing in ASD, in particular. Yet, the current findings show that both global interference and a global precedence was exhibited by autistic and NT adults alike. Hence, in line with the conclusions of Van der Hallen et al. (2015), the current findings have not provided any support for either the WCC and EPF theories.

The current findings do not support previously suggested atypical processing of global information in the presence of incongruent local information in autistic individuals (Van der Hallen et al., 2015). Other studies have previously found atypical hierarchical processing in samples of autistic children and adolescents when the currently utilized Navon's paradigm has been used (e.g. Plaisted et al., 1999; Rinehart et al., 2000). Yet, that was not the case in other studies focusing on adolescent only samples (e.g. Mottron et al., 2003). Thus, it should be acknowledged that the lack of group differences in the current adult 
sample, could further suggest potential differences in developmental trajectories with hierarchical processing atypicalities in autism lessening with age.

It is worth noting that Van der Hallen et al. (2015) observed subtle age effects their meta-analysis suggesting a difference in the pace of developmental course between autistic and NT individuals. Developmental changes in hierarchical processing are also supported by research showing that older NT adults process information at the local level faster than the global level (i.e. the global precedence effect disappears) in contrast to global precedence in young adults (Lux, Marshall, Thimm, \& Fink, 2008). If this was also the case in ASD, one would expect a similar process with the local processing bias, or superiority, increasing with age in autistic adults (Happé \& Charlton, 2012). This idea of change in adulthood from primarily global to more local processing is in line with current findings showing local interference in NT participants. The lack of group differences, despite careful age matching, however, indicates that the development of hierarchical processing may follow a different trajectory in NT and ASD. Longitudinal studies are therefore needed to investigate the existence of these developmental pathways.

In addition to age, other types of personal variability might be related to local and global processing. It is possible that rather than the existence of an ASD diagnosis, it is the heterogeneity in relevant autistic characteristics that may be underlying previously inconsistent findings of atypical hierarchical processing atypicalities. For example, DiCriscio and Troiani (2017) have previously reported a gender specific link between visual form perception and aloofness, but not other broader autism phenotype characteristics. Current findings indicate that atypical local/global integration may not be a universal in ASD. Yet, it does not preclude a possibility that it would have occurred in, for example, the more aloof subgroup of participants. Whilst identification of such groups was out of the scope for the 
current study, future research is needed to disentangle the relative contribution of different autistic characteristics to hierarchical perception.

In conclusion, this is the first study using a traditional divided attention task with Navon's hierarchical figures to show a global precedence with both global and local interference effects in autistic adults. As both effects were also exhibited by NT adults these results could not be explained by either the WCC or EPF theories of atypical hierarchical processing. The current study, instead, suggests that atypical hierarchical processing does not persist into adulthood in autistic individuals. Yet, in light of previous research, it supports potential differences in the developmental trajectories of local/global processing by suggesting plausible age-related increases to local information processing in neurotypicals. 
GLOBAL AND LOCAL PROCESSING IN ASD

Disclosure of Interest

The authors report no conflict of interest. 


\section{References}

Baron-Cohen, S., Wheelwright, S., Skinner, R., Martin, J., \& Clubley, E. (2001). The autismspectrum quotient (AQ): evidence from Asperger syndrome/high-functioning autism, males and females, scientists and mathematicians. Journal of Autism and Developmental Disorders, 31(1), 5-17. https://doi.org/10.1023/A:1005653411471

Cribb, S. J., Olaithe, M., Di Lorenzo, R., Dunlop, P. D., \& Maybery, M. T. (2016). Embedded Figures Test Performance in the Broader Autism Phenotype: A Metaanalysis. Journal of Autism and Developmental Disorders, 46(9), 2924-2939. https://doi.org/10.1007/s10803-016-2832-3

Dale, G., \& Arnell, K. M. (2013). Investigating the stability of and relationships among global/local processing measures. Attention, Perception, \& Psychophysics, 75(3), 394406. https://doi.org/10.3758/s13414-012-0416-7

DiCriscio, A. S., \& Troiani, V. (2017). Brief Report: Autism-like Traits are Associated With Enhanced Ability to Disembed Visual Forms. Journal of Autism and Developmental Disorders, 47(5), 1568-1576. https://doi.org/10.1007/s10803-017-3053-0

Dienes, Z. (2014). Using Bayes to get the most out of non-significant results. Frontiers in Psychology, 5. https://doi.org/10.3389/fpsyg.2014.00781

Field, A., \& Wright, D. (2011). A Primer on Using Multilevel Models in Clinical and Experimental Psychopathology Research. Journal of Experimental Psychopathology, 2(2), 271-293. https://doi.org/10.5127/jep.013711

Frith, U. (1989). Autism: Explaining the enigma. Oxford, England: Blackwell Scientific Publications.

Frith, U., \& Happé, F. (1994). Autism: Beyond "theory of mind." Cognition, 50(1-3), 115132. https://doi.org/10.1016/0010-0277(94)90024-8

Happé, F. (1996). Studying weak central coherence at low levels: Children with autism do 
not succumb to visual illusions. A research note. Journal of Child Psychology and Psychiatry and Allied Disciplines, 37(7), 873-877. https://doi.org/10.1111/j.14697610.1996.tb01483.x

Happé, F., \& Charlton, R. a. (2012). Aging in autism spectrum disorders: A mini-review. Gerontology, 58(1), 70-78. https://doi.org/10.1159/000329720

Happé, F., \& Frith, U. (2006). The weak coherence account: detail-focused cognitive style in autism spectrum disorders. Journal of Autism and Developmental Disorders, 36(1), 525. https://doi.org/10.1007/s10803-005-0039-0

Hox, J. (2010). Multilevel analysis: Techniques and applications (2nd.). Hove, East Sussex: Routledge.

JASP Team. (2018). JASP (Version 0.9)[Computer software]. [Computer Software].

Lenth, R. (2018). Emmeans: estimated marginal means. Aka Least-Squares Means.

Levy, A., \& Perry, A. (2011). Outcomes in adolescents and adults with autism: A review of the literature. Research in Autism Spectrum Disorders, 5(4), 1271-1282. https://doi.org/10.1016/j.rasd.2011.01.023

Lord, C., Rutter, M., DiLavore, P., Risi, S., Gotham, K., \& Bishop, S. (2012). Autism Diagnostic Observation Schedule-2nd edition (ADOS-2). Los Angeles, CA: Western Psychological Corporation.

Lux, S., Marshall, J. C., Thimm, M., \& Fink, G. R. (2008). Differential processing of hierarchical visual stimuli in young and older healthy adults: Implications for pathology. Cortex, 44(1), 21-28. https://doi.org/10.1016/j.cortex.2005.08.001

Mottron, L., \& Belleville, S. (1993). A Study of Perceptual Analysis in a High-Level Autistic Subject with Exceptional Graphic Abilities. Brain and Cognition, 23(2), 279-309. https://doi.org/10.1006/brcg.1993.1060

Mottron, L., Burack, J. A., Iarocci, G., Belleville, S., \& Enns, J. T. (2003). Locally oriented 
perception with intact global processing among adolescents with high-functioning autism: Evidence from multiple paradigms. Journal of Child Psychology and Psychiatry and Allied Disciplines, 44(6), 904-913. https://doi.org/10.1111/1469-7610.00174

Mottron, L., Dawson, M., Soulières, I., Hubert, B., \& Burack, J. A. (2006). Enhanced perceptual functioning in autism: an update, and eight principles of autistic perception. Journal of Autism and Developmental Disorders, 36(1), 27-43. https://doi.org/10.1007/s10803-005-0040-7

Navon, D. (1977). Forest before trees: The precedence of global features in visual perception. Cognitive Psychology, 9(3), 353-383. https://doi.org/10.1016/0010-0285(77)90012-3

O’Riordan, M. A., Plaisted, K., Driver, J., \& Baron-Cohen, S. (2001). Superior visual search in autism. Journal of Experimental Psychology: Human Perception and Performance, 27(3), 719-730. https://doi.org/10.1037/0096-1523.27.3.719

Ozonoff, S., Strayer, D. L., McMahon, W. M., \& Filloux, F. (1994). Executive function abilities in autism and Tourette syndrome: an information processing approach. Journal of Child Psychology and Psychiatry, and Allied Disciplines, 35(6), 1015-1032. https://doi.org/10.1111/j.1469-7610.1994.tb01807.x

Pinheiro, J., Bates, D., DebRoy, S., \& Sarkar, D. (2016). nlme: Linear and Nonlinear Mixed Effects Models [R package]. R Package Version.

Plaisted, K., O’Riordan, M., \& Baron-Cohen, S. (1998). Enhanced Visual Search for a Conjunctive Target in Autism: A Research Note. Journal of Child Psychology and Psychiatry, 39(5), S0021963098002613. https://doi.org/10.1017/S0021963098002613

Plaisted, K., Swettenham, J., \& Rees, L. (1999). Children with autism show local precedence in a divided attention task and global precedence in a selective attention task. Journal of Child Psychology and Psychiatry, and Allied Disciplines, 40(5), 733-742.

Rinehart, N. J., Bradshaw, J. L., Moss, S. A., Brereton, A. V., \& Tonge, B. J. (2000). 
Atypical interference of local detail on global processing in high-functioning autism and Asperger's disorder. Journal of Child Psychology and Psychiatry, and Allied Disciplines, 41, 769-778. https://doi.org/10.1111/1469-7610.00664

Rondan, C., \& Deruelle, C. (2007). Global and configural visual processing in adults with autism and Asperger syndrome. Research in Developmental Disabilities, 28(2), 197206. https://doi.org/10.1016/j.ridd.2006.02.007

Ropar, D., \& Mitchell, P. (2001). Susceptibility to Illusions and Performance on Visuospatial Tasks in Individuals with Autism. Journal of Child Psychology and Psychiatry, 42(4), 539-549. https://doi.org/10.1111/1469-7610.00748

Scherf, S. K., Luna, B., Kimchi, R., Minshew, N., \& Behrmann, M. (2008). Missing the big picture: Impaired development of global shape processing in autism. Autism Research, 1(2), 114-129. https://doi.org/10.1002/aur.17

Shah, A., \& Frith, U. (1983). An Islet of Ability in Autistic Children: A Research Note. Journal of Child Psychology and Psychiatry, 24(4), 613-620. https://doi.org/10.1111/j.1469-7610.1983.tb00137.x

Shah, A., \& Frith, U. (1993). Why Do Autistic Individuals Show Superior Performance on the Block Design Task? Journal of Child Psychology and Psychiatry, 34(8), 1351-1364. https://doi.org/10.1111/j.1469-7610.1993.tb02095.x

Simmons, D. R., \& Todorova, G. K. (2018). Local Versus Global Processing in Autism: Special Section Editorial. Journal of Autism and Developmental Disorders, 48(4), 13381340. https://doi.org/10.1007/s10803-017-3452-2

Tabachnick, B. G., \& Fidell, L. S. (2007). Using multivariate statistics (5th ed.). Boston: Pearson Education, Inc.

Van der Hallen, R., Evers, K., Brewaeys, K., Van den Noortgate, W., \& Wagemans, J. (2015). Global processing takes time: A meta-analysis on local-global visual processing 
in ASD. Psychological Bulletin, 141(3), 549-573. https://doi.org/10.1037/bul0000004

Van Eylen, L., Boets, B., Steyaert, J., Wagemans, J., \& Noens, I. (2018). Local and Global Visual Processing in Autism Spectrum Disorders: Influence of Task and Sample Characteristics and Relation to Symptom Severity. Journal of Autism and Developmental Disorders, 48(4), 1359-1381. https://doi.org/10.1007/s10803-015-25262

Wagenmakers, E. J., Wetzels, R., Borsboom, D., \& van der Maas, H. L. J. (2011). Why Psychologists Must Change the Way They Analyze Their Data: The Case of Psi: Comment on Bem (2011). Journal of Personality and Social Psychology, 100(3), 426432. https://doi.org/10.1037/a0022790 


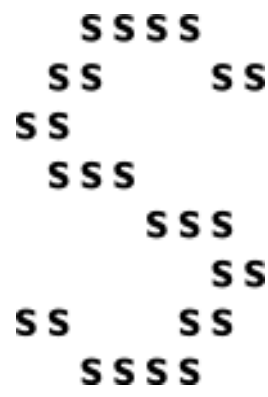

$\mathbf{x x} \quad \mathbf{x x}$

$x \mathbf{x} \quad \mathbf{x x}$

$x x \quad x x$

$\operatorname{XXXXXXXX}$

$\operatorname{XXXXXXXX}$

$\mathbf{X X} \quad \mathbf{x X}$

$\mathbf{x x} \quad \mathbf{x x}$

S S S S

$\mathbf{x x} \quad \mathbf{x x}$ 
Figure Caption

Figure 1. Example stimuli used in the Navon's hierarchical figures task. A congruent stimulus is presented on the left and incongruent stimulus is presented on the right. 
Table 1

Participant Comparison on Age, IQ, and AQ per Diagnosis

\begin{tabular}{|c|c|c|c|c|c|c|c|c|}
\hline & \multicolumn{3}{|c|}{$\operatorname{ASD}(n=27)$} & \multicolumn{3}{|c|}{$\mathrm{NT}(n=25)$} & \multirow{2}{*}{$t(50)$} & \multirow{2}{*}{$p$} \\
\hline & $M$ & $S D$ & Range & $M$ & $S D$ & Range & & \\
\hline Age & 38.22 & 13.87 & $18-63$ & 36.61 & 13.84 & $19-64$ & -0.42 & .677 \\
\hline FSIQ & 110.33 & 14.44 & $77-134$ & 110.68 & 11.19 & $83-125$ & 0.10 & .924 \\
\hline VIQ & 107.59 & 14.64 & $71-129$ & 109.04 & 10.72 & $81-127$ & 0.40 & .688 \\
\hline PIQ & 111.00 & 14.05 & $80-136$ & 110.32 & 12.65 & $84-138$ & -0.18 & .856 \\
\hline AQ & 34.93 & 6.72 & $21-48$ & 18.64 & 5.95 & $5-29$ & -9.22 & $<.001$ \\
\hline ADOS-2 & 9.78 & 3.42 & $3-17$ & $\mathrm{n} / \mathrm{a}$ & $\mathrm{n} / \mathrm{a}$ & $\mathrm{n} / \mathrm{a}$ & $\mathrm{n} / \mathrm{a}$ & $\mathrm{n} / \mathrm{a}$ \\
\hline
\end{tabular}

Note. FSIQ = full scale IQ, VIQ = verbal IQ, PIQ = performance IQ, AQ = Autism Spectrum

Quotient, ADOS-2 = Autism Diagnostic Observation Schedule, Second Edition 
Table 2

Means (M) and Standard Deviations (SD) of Reaction Time (ms) per Diagnosis and Target Presentation Level

\begin{tabular}{|c|c|c|c|c|}
\hline & \multicolumn{2}{|c|}{$\operatorname{ASD}(n=27)$} & \multicolumn{2}{|c|}{ NT $(n=25)$} \\
\hline & $M$ & $S D$ & $M$ & $S D$ \\
\hline Congruent & 723.45 & 373.49 & 687.75 & 288.17 \\
\hline Global & 838.33 & 423.15 & 784.82 & 321.65 \\
\hline Local & 930.87 & 433.46 & 861.93 & 304.72 \\
\hline
\end{tabular}

Note. The average scores for each condition are presented here. For subsequent analyses, logtransformed data were used. 